\title{
LA CRISIS DE 1873 Y LA DEUDA EXTERNA LATINOAMERICANA: UNA REEVALUACION CRITICA
}

\author{
CARLOS MARICHAL \\ Universidad Autónoma Metropolitana \\ México, D. F.
}

Hace algunos años, el historiador inglés D. C. M. Platt publicó un incisivo artículo en el Economic History Review en el cual hizo un llamado para que se efectuara una revisión global de las estimaciones estadísticas de las exportaciones de capital británico a lo largo del siglo XIX ${ }^{1}$. Más recientemente, el mismo autor ha publicado un libro que profundiza en esta temática y que está destinado a provocar cambios significativos en la manera en que los historiadores interpretan la cantidad, el origen, las funciones y la distribución de la inversión de capital en Europa y Estados Unidos desde 1815 hasta $1870^{2}$. En esencia, Platt argumenta que la mayor parte del capital para la industrialización en dichas regiones provino de fuentes locales o «domésticas» y que, en contraste, la exportación de capitales británicos fue de menor importancia en este proceso de lo que habitualmente se supone.

Los planteamientos de Platt tienen una especial relevancia para la historia económica latinoamericana, pues durante demasiado tiempo se ha escrito acerca del impacto del imperialismo financiero europeo en la región sin contar con una base empírica mínimamente sólida. En efecto, son muy infrecuentes los trabajos en los cuales se intente formular una estimación de las series anuales de las exportaciones de capitales hacia América Latina durante el siglo XIX $o$, inclusive, para el primer tercio del siglo $\mathrm{xx}^{3}$. En este ensayo intentaremos efectuar un balance y una reevaluación de los montos de los préstamos externos que recibieron los Estados latinoamericanos entre 1850 y 1875. Para cumplir con este objetivo ofreceremos una síntesis y crítica de los datos estadísticos disponibles, los cuales acompañaremos con un análisis de la compleja mecánica de la emisión de los empréstitos. Ello nos dará pie, a su vez, para considerar a grandes rasgos cuál fue el impacto de la gran crisis de 1873 sobre el endeudamiento externo latinoamericano.

'D. C. M. Platt (1980), pp. 1-16.

D. C. M. Platt (1984).

Una excepción es el caso argentino, ya que existen dos estudios que proporcionan este tipo de material para los años 1880-1914; véanse J. Williams (1920) y A. G. Ford (1966). Para una revisión sintética de materiales adicionales, véase Marichal (1980). 
El debate acerca de la exportación de capitales europeos: cantidad $y$ distribución

Las primeras estimaciones, algo rudimentarias, del monto de las exportaciones de capitales británicos comenzaron a publicarse precisamente a raíz del estallido de la crisis económica internacional de 1873. Los autores, Dudley Baxter, Robert Giffen y Hyde Clarke, ofrecieron en las salas del Statistical Society de Londres una serie de estudios detallados para su consideración y crítica por parte de sus colegas. Dichos ensayos, posteriormente publicados en la revista de este club académico, incluían una abundancia de datos acerca del papel del capital británico en el endeudamiento externo de gran número de países, incluyendo los latinoamericanos ${ }^{4}$. Estos materiales fueron recogidos y ampliados posteriormente por escritores como George Paish y C. K. Hobson, quienes a principios de siglo presentaron nuevas estimaciones de la inversión internacional de los fondos británicos ${ }^{5}$.

En 1927, el historiador norteamericano Leland Jenks retomó el tema redactando un trabajo, que todavía es un clásico, sobre la exportación de capitales ingleses desde la época postnapoleónica hasta $1875^{\circ}$. Pero Jenks no intentó una reevaluación muy detallada o sistemática de las estadísticas; argumentaba que la importancia de esta «migración» de capitales fue de gran peso, pero quizá no tanto como habían sugerido algunos de sus predecesores. Tres años más tarde se publicó el igualmente notable trabajo de Herbert Feis sobre el rol de los capitales europeos en la economía mundial entre 1870 y $1914^{?}$. Feis, como Jenks, se interesaba más en la relación entre finanzas y política que en algunos de los aspectos técnicos de su tema, y por ello posiblemente aceptó estimaciones muy altas de las transferencias internacionales de capitales.

Más recientemente, en cambio, se han publicado una serie de trabajos que tienden a criticar las estimaciones tradicionales, sugiriendo que deben reducirse sustancialmente. En esta línea se insertan Albert Imlah y Alexander Cairncross, quienes, en base a la reconstrucción histórica de la balanza de pagos inglesa, ofrecieron una serie de cálculos del monto real de las exportaciones de capitales más moderadas que las prevalecientes hasta entonces ${ }^{8}$. Dentro de esta línea también se sitúa $\mathrm{D}$. C. M. Platt, quien ha utilizado los ricos archivos de la casa Baring (una de las firmas financieras británicas con mayor influencia durante el siglo xIx) para ofrecer una visión novedosa y más realista de la complejidad de las transacciones financieras de la época.

- Véanse D. Baxter (1874), H. Clarke (1878) y R. Giffen (1904).

${ }^{5}$ C. K. Hobson (1914) y G. Paish (1977).

- L. Jenks (1927).

${ }^{7}$ H. Feis (1930).

A. Imlah (1958) y A. K. Cairncross (1953). 
Platt sugiere que debe reducirse la estimación de 1.000 millones de capital británico invertido en el exterior para el año 1875 a, aproximadamente, 500 millones (de los cuales, menos de 15 por 100 en América Latina). Argumenta que ello se explica por el hecho de que una gran proporción de las inversiones efectuadas a través de Londres eran realizadas por capitalistas, de otros países y que, por ende, los rentistas ingleses tenían una participación menos importante de lo que podría suponerse a primera vista. Por otro lado, señala con enorme acopio de ejemplos que una proporción significativa de los empréstitos internacionales contemporáneos eran emitidos simultáneamente en varios mercados de capitales europeos. En sintesis:

La sobreestimación de la exportación de capitales ha surgido de varias suposiciones poco plausibles; por ejemplo: que los empréstitos públicos siempre lograsen colocación en el mercado; que fueron comprados por los ciudadanos del país donde estaba ese mercado financiero; que los valores «nominales» $y$ «reales» eran virtualmente idénticos... 9 .

Para un análisis del endeudamiento externo de América Latina en el período es necesario tener en cuenta estas consideraciones. Para comenzar, no se pueden aceptar acríticamente las cifras de los valores nominales de los empréstitos, sino que resulta indispensable efectuar una evaluación más precisa, caso por caso, si fuera posible. En este sentido, es pertinente observar que, entre 1850 y 1875 , un número no despreciable de los empréstitos peruanos, mexicanos, centroamericanos, etc., se emitieron simultáneamente en Londres, en París e, inclusive, en algunos otros mercados de la Europa continental. Por otro lado, hay que estudiar el reverso de la moneda, es decir, cuál fue el verdadero peso de la deuda para los países latinoamericanos, cuánto recibieron en efectivo y cuánto pagaron. En fin, son éstas varias preguntas a las que intentaremos aproximarnos, comenzando con el problema de la medición serial.

\section{La medición de los flujos de capital bacia América Latina}

Si bien parece necesario aceptar que las estimaciones tradicionales de los flujos de capitales internacionales a mediados del siglo XIX han sido exageradamente altas, en el caso latinoamericano dichas críticas carecen de sentido hasta que se disponga de series estadísticas más o menos confiables. Por desgracia, no existen todavía series anuales para las transferencias de capitales

' D. C. M. Platt (1984), p. 3. 
franceses, alemanes, belgas, holandeses o españoles durante el siglo xIx o principios del siglo $\mathrm{xx}$; apenas contamos con alguna que otra estimación global para ciertos años aislados ${ }^{10}$. Por fortuna, en cambio, sí disponemos de series anuales para 1865-1914 referentes a las exportaciones de capitales británicos hacia América Latina, elaboradas por Mathew Simon, y también unas estimaciones de conjunto para cada decenio desde 1825 hasta 1914, formuladas por Irving Stone ". Debe agregarse que, para el caso de América Latina, esta in. formación tiene una indudable importancia debido al peso preponderante (pero no exclusivo) del capital británico en el total de las transferencias externas durante el siglo xIx ${ }^{12}$.

Comenzaremos con un comentario sucinto y crítico de la metodología y fuentes utilizadas para reunir estas cifras, para luego pasar a un análisis general de las principales tendencias a corto y mediano plazo, comparándolas con algunas series del comercio exterior.

Al presentar sus series anuales de transferencias de capital británico, Simon comienza por reconocer ciertas deficiencias en las fuentes que él maneja, que son, primordialmente, los informes semanales y mensuales de la prensa financiera londinense acerca de la emisión y venta de bonos de gobiernos y acciones de compañías extranjeras ${ }^{13}$. Señala que estas cifras son inversiones de cartera (portfolio) y, por lo tanto, no nos dicen nada acerca de movimientos de capitales a corto plazo (por ejemplo, ciertas transferencias interbancarias) y no incluyen datos acerca de las inversiones directas que podían efectuar individuos o empresas británicas sin pasar por la Bolsa, Pero, al mismo tiempo, Simon defiende sus series recordando que la «inversión de cartera» era la más importante en lo que se refiere al conjunto de las transacciones internacionales de capital británico en el siglo $\mathrm{XIX}^{14}$.

Los datos anuales comienzan desde 1865 , porque fue a partir de entonces que la revista Investor's Montbly Manual inició su recopilación y publicación

10 Para el caso de las inversiones francesas en América Latina, véase F. Mauro (1977).

"M. Simon (1963), pp. 15-44, e I. Stone (1962) y (1977).

12 Se puede estimar que cerca de una quinta parte del total de los bonos externos latinoamericanos del período se emitieron en París; entre ellos, préstamos de Perú, Costa Rica, Honduras, Haití y una pequeña porción de valores brasileños. A su vez, puede estimarse que un porcentaje menor, quizá $5-10$ por 100 , estaba en manos de inversores holandeses; entre ellos, bonos antiguos de Colombia, Venezuela, Ecuador y algunos pocos argentinos y mexicanos.

"Simon utilizó el Investor's Montbly Manual, el Economist, el London Times, el Bankers Magazine e información proveniente de los Jenks Files, un archivo particular donado por Leland Jenks. Simon (1968), p. 21.

${ }_{14}$ A. Hall critica las estimaciones de Simon, señalando diversos rubros no incluidos como son las transferencias interbancarias, aunque puede suponerse que para el período 1850-1880 y para la región latinoamericana, en particular, sus críticas no resultan demoledoras; en cambio, sí lo serían para el período de 1880-1914 o épocas posteriores. A. R. Hall (1968), p. 13. 
regular. Simon agrupa sin desglosar tanto las cifras de bonos de gobiernos extranjeros como las de acciones de firmas privadas que operaban en el exterior. Por consiguiente, tales series no pueden representar una medición fiel del endeudamiento estatal latinoamericano, por ejemplo. Aun así, debe reconocerse que representan una aproximación, ya que, de acuerdo con las cifras desglosadas de Stone para 1865 y 1875 , los empréstitos gubernamentales representaban algo más del 80 por 100 del total de las inversiones inglesas en la región ${ }^{15}$. El valor de las series de Simon radica en sugerir cuáles fueron las tendencias principales, siendo particularmente ilustrativas las fluctuaciones a corto plazo. No obstante, para tener una idea de su significado hay que compararlas con otras series económicas (véanse gráficos I y II).

En el gráfico I se comparan las curvas de las exportaciones de mercancías y de capitales británicos hacia América Latina en el período 1855-80. Allí puede constatarse -como es bien sabido- que ésta fue una época de rápida expansión mercantil; se incluyen y contrastan aquí las cifras brasileñas con las globales, porque Brasil seguía siendo el país de la región con mayor nivel de comercio exterior y, además, porque las fluctuaciones de su comercio tendían a corresponder más estrechamente con las tendencias generales. Dichas tendencias muestran un crecimiento relativamente sostenido del comercio hasta 1873 , siendo interrumpido esporádicamente por pequeñas inflexiones decrecientes en $1857-58$ (crisis internacional de 1857), en $1860-62$ y en $1866-68$ (crisis internacional de 1866). Después de 1873, en cambio, se produce una caída prolongada que corresponde a la depresión económica mundial de esos años.

En contraste con los flujos de mercancías, las transferencias de capitales británicos resultan mucho más erráticas, haciéndose notar el auge particularmente abrupto de 1869-73 y el descenso igualmente marcado en el período inmediatamente siguiente. La principal conclusión a la que puede llegarse al respecto, a partir de las cifras globales del gráfico I y de las cifras argentinas del gráfico II, es que los movimientos de los fondos financieros eran sustancialmente más accidentados que los de las mercancías ${ }^{16}$. En lo que se refiere a la crisis de 1873 sugieren claramente que su impacto fue mayor en la esfera financiera que en otras esferas de la actividad económica.

Un problema distinto se plantea si, en vez de analizar series, proponemos estimar el monto total de la deuda externa de uno o más países latinoamericanos en un año dado para evaluar su peso y el del servicio de la deuda. Stone proporciona una serie de estimaciones globales (altamente criticables) del valor

is Véase el Apéndice al final de este artículo.

${ }^{16}$ Los datos para transferencias de capital británico a Argentina utilizados en el gráfico II son los únicos publicados por Simon que se refieran a un país individual; todos los demás datos que publicó eran agregados para varios países. 


\section{GRAFICO I}

Exportaciones de mercancías y de capitales británicos a América Latina, $1855-1880$

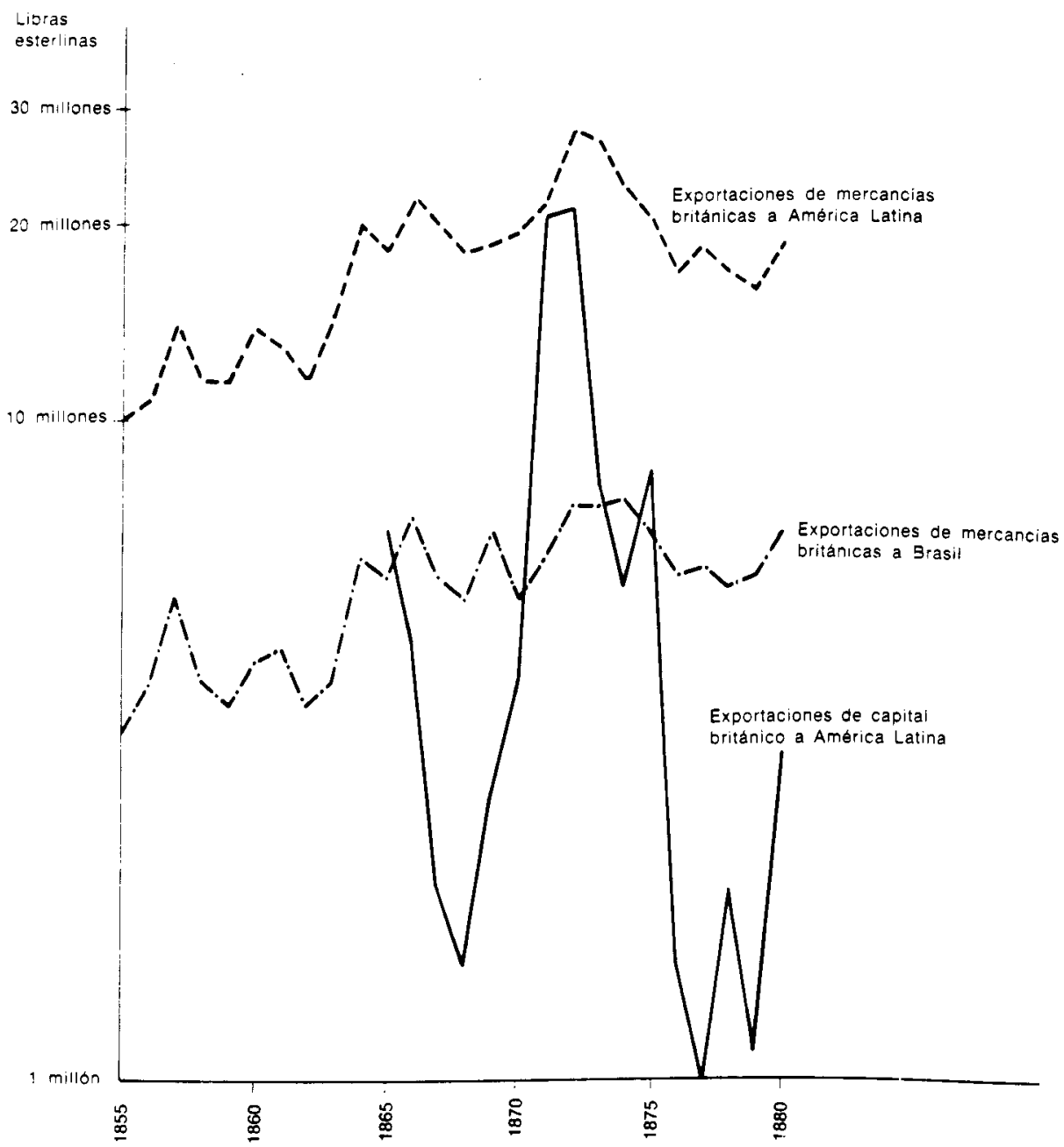

Fuentes: D. C. M. Platr, Latin America and British Trade, 1806-1914 (Londres, 1972), pp. 316-317; Mathew Sim ON, *The Pattern of New British Portfolio Foreign Investment, 1865.1914*, en A. R. Hall (ed.), The Export of Capital from Britain, 1870-1914 (Londres, 1968), pp. 39-40. 


\section{GRAFICO II}

Exportaciones de mercancias y de capitales británicos a Argentina, 1850-1880

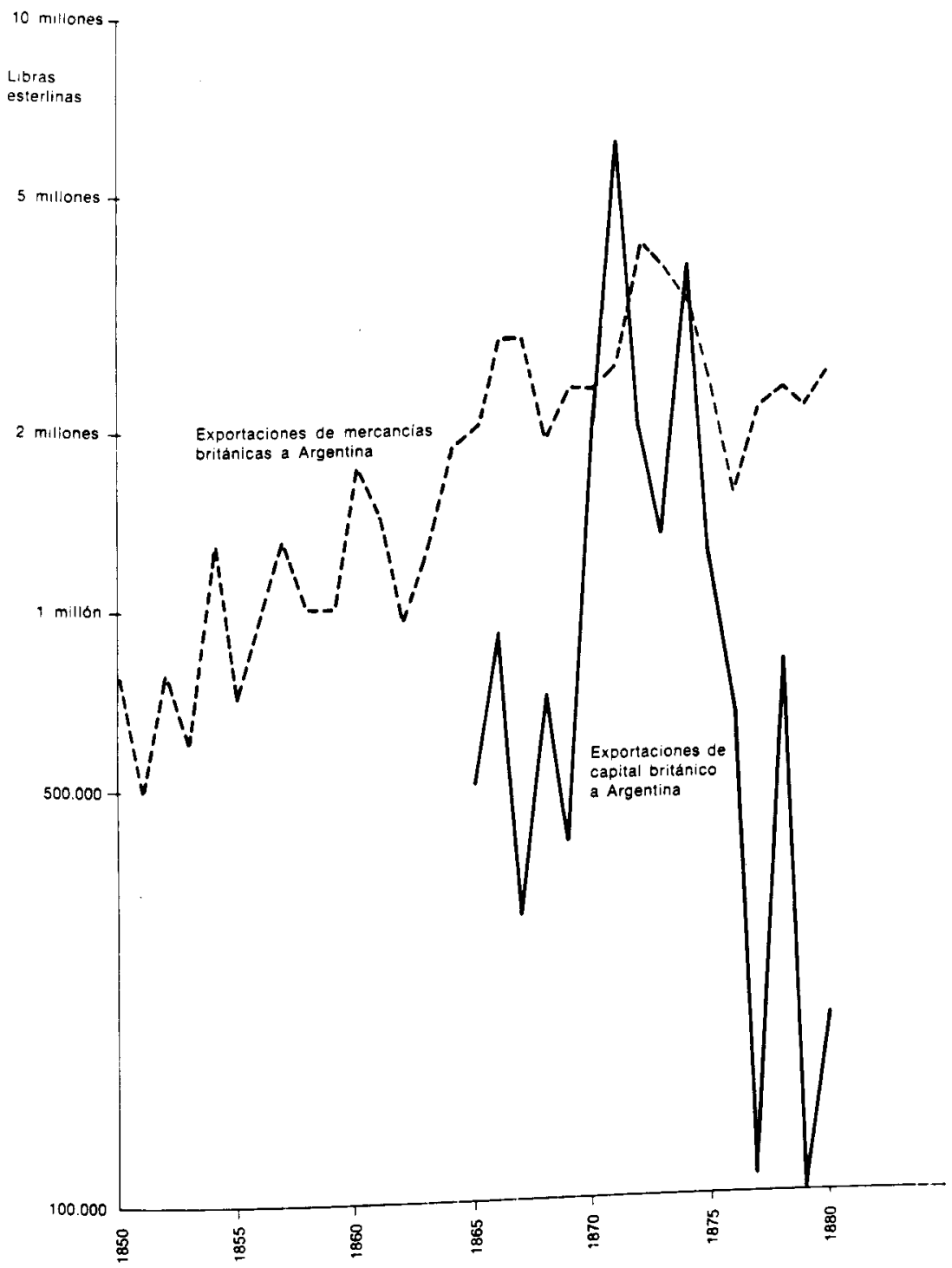

Fuentes: D. C. M. Platt, Latin America and British Trade, 1806-1914 (Londres, 1972), pp. 316-317; Irving StONE, *British Investment in Argentina*, Journal of Economic History, 32, núms. 1-2 (junio 1972), pp. 546-547. 
total de los bonos gubernamentales latinoamericanos emitidos en Londres. De acuerdo con su cálculo, la deuda externa latinoamericana pendiente de pago en 1865 se aproximaba a los 60 millones de libras esterlinas y algo más de 120 millones en 1875. Aparte del crecimiento bastante marcado, sus datos indican que en este período los préstamos constituían el grueso de las inversiones totales británicas en la región. En otras palabras, la inversión directa en empresas privadas todavía no tenía gran importancia.

Pero ¿cómo de confiables son las cifras sobre las deudas? Un análisis más detallado - utilizando documentos contables gubernamentales contemporáneos- sugiere que hay que manejar la información con pinzas. Ello no debe sorprendernos, pues aun los escritores mejor informados de la época desconfiaban, tanto de las cifras oficiales de la Bolsa de Londres como de los informes gubernamentales. En 1874, Dudley Baxter afirmaba: «Casi todas las estadísticas de Deudas Nacionales son aproximaciones y no pueden considerarse como tales exactas» ${ }^{17}$. Hyde Clarke, para entonces secretario de la Corporación de Tenedores de Bonos Extranjeros, ratificaba esa opinión, afirmando: "La naturaleza precisa y el grado de las operaciones que se llevan a cabo en el mercado de préstamos de Londres no puede ser averiguado con certeza" ${ }^{18}$. $\mathrm{Y}$ a ello se agregaba otro problema, igualmente espinoso, que se refería a la distribución de los bonos en varios mercados distintos. Como señalaba L. Cohen, el banquero, al comentar el estudio de Clarke: «En ciertos días hay entre dos y tres millones de libras en bonos y acciones que van de una ciudad a otra - de Londres a París, y viceversa-, de manera tal que es imposible decir al fin del año cuántos millones de títulos han cambiado de manos» ${ }^{19}$.

En realidad, la única forma de lograr una aproximación más o menos certera del monto de las deudas externas latinoamericanas de la época depende de la posibilidad de comparar los datos financieros europeos con cifras confiables de la contabilidad financiera de los Ministerios de Hacienda de los países latinoamericanos. Esto es precisamente lo que hemos intentado para algunos empréstitos argentinos, y a partir de ello podemos ofrecer una crítica de las estimaciones de Stone (las cuales están basadas solamente en datos de la Bolsa londinense). Stone indica que la deuda externa argentina pendiente de pago en 1875 se aproximaba a 16.500 .000 libras esterlinas. Sin embargo, el análisis del excelente informe del Ministerio de Hacienda de Argentina para el año de 1876 nos indica que la deuda externa del gobierno nacional no sobrepasaba los 8.460 .000 libras $^{20}$. A ellos tenemos que agregar unos 2.540 .000

17 D. Baxter (1874), p. 2.

is. Clarke (1878), p. 311.

19 H. Clarke (1878), p. 343.

20 República Argentina, Ministerio de Hacienda, Memoria del Ministerio de Hacienda (1876), sección II, parte IV, pp. 83-84, y la misma Memoria para el año 1880, p. 100. 
libras de las deudas de los gobiernos provinciales de Buenos Aires, Santa Fe y Entre Ríos. En total tenemos entonces una cifra global de 11 millones, o sea, un 33 por 100 más baja que la estimación de Stone.

$\mathrm{La}$ determinación de las cifras reales, por lo tanto, no sólo proporciona una idea más precisa del peso global de la deuda externa, sino que, además, resulta indispensable para calcular el elemento clave del «servicio de la deuda». De acuerdo con los informes contables nacionales y provinciales argentinos de 1876 , se puede estimar que el servicio de la deuda externa absorbió unos 1.110 .000 libras esterlinas en el año de 1876, lo cual era equivalente a un 10 por 100 de los ingresos totales del país por concepto de exportaciones. Esta cifra relativamente baja es significativa en tanto puede ayudar a explicar por qué el gobierno no se vio obligado a suspender pagos durante los años de depresión económica generalizada de $1873-80$, en contraste con otros Estados latinoamericanos.

El ejemplo señalado, sin embargo, es solamente uno entre muchos que requiere una cuidadosa revisión. Para alcanzar una visión aproximada del peso del endeudamiento externo sobre las economías latinoamericanas al tiempo del estallido de la crisis de 1873 tendríamos que disponer de una multitud de estudios especializados sobre cada uno de los empréstitos. Por el momento, y dadas las carencias de la historiografía, nos limitaremos a proporcionar una serie de comentarios críticos acerca de las cifras bursátiles oficiales.

\section{Los empréstitos externos latinoamericanos, 1850-73}

El cuarto de siglo que precedió a la debâcle financiera de 1873 fue testigo de un incremento sustancial de las deudas externas de virtualmente todos los países latinoamericanos. En el decenio de $1850-60$ se emitieron pocos empréstitos nuevos, ya que la mayoría de las transacciones financieras se limitaron, más bien, a renegociar o «convertir» deudas anteriores todavía pendientes de pago. Pero, a partir de 1860 , el número de nuevos bonos latinoamericanos que se pusieron a la venta en los mercados europeos ascendió con considerable rapidez, y entre 1869 y 1873 se experimentó un verdadero boom de préstamos tomados por los gobiernos de los países grandes y chicos de la región. Para entonces, los agentes financieros de Argentina, Brasil y Perú, pero también de Estados menos conocidos y menos solventes, como Paraguay, Costa Rica, Honduras, Santo Domingo y Bolivia, acudieron a los distritos financie. ros de Londres y París para solicitar fondos frescos de los banqueros e inversores.

¿Cómo podemos evaluar el nivel y el tipo de endeudamiento alcanzado en esos años? El primer paso consiste sencillamente en elaborar una lista ba. 
sada en la información oficial bursátil de los empréstitos emitidos (véanse cuadro I y Apéndice). Pero, como ya se ha indicado, dicha información tiene que ser sometida a un proceso de análisis crítico. Para determinar la transferencia «real» o «neta» de recursos logrados a través de estos préstamos, es necesario conocer más de cerca los mecanismos de emisión de los empréstitos y de su posterior realización.

Observemos, en primer lugar, que el cuadro I consigna solamente los valores «nominales» de los empréstitos emitidos. Es decir, se refiere a los montos que los Estados latinoamericanos prometieron devolver, pero no a las sumas «reales» que recibieron, las cuales eran siempre sustancialmente inferiores. Las sumas recibidas eran menores porque había que descontar tres rubros: 1) la diferencia entre el valor nominal y la cotización efectiva a la cual se vendieron los bonos; 2) las comisiones y gastos cobrados por los banqueros por vender los títulos; 3) las reservas retenidas por los banqueros para servir de garantía de pago para los primeros tramos de intereses y amortización.

Para estimar cuál fue el monto de los fondos transferidos de Europa a América Latina, el primer problema consiste, por lo tanto, en precisar cuál fue el precio efectivo de venta de los títulos. El valor «nominal» de los mismos era invariablemente de 100 , pero ello no implicaba que se lograsen vender a ese precio. Durante el período bajo estudio, los países que lograron vender sus bonos a niveles relativamente altos fueron Argentina, Brasil y Chile - con un promedio de cerca de 88 por 100 del valor nominal- (véanse datos en Apéndice). Ello puede atribuirse a que los inversores europeos tenían confianza en la capacidad de pago de dichos Estados por su alto nivel de comercio exterior $y$, por ende, de ingresos fiscales. Algo menos alto se cotizaba el crédito peruano, con un promedio cercano a 80 por 100; aun así, el Estado peruano logró vender una mayor cantidad de bonos que cualquier gobierno latinoamericano en estos años, convirtiéndose en uno de los mayores deudores a nivel mundial ${ }^{21}$. Mucho menos apreciados por los rentistas europeos eran los valores de países como Santo Domingo, Uruguay, Guatemala o Bolivia, que apenas lograban una cotización de entre 60 y 70 por 100 .

Esta información permite calcular grosso modo qué cantidades los gobier-

${ }^{21}$ Las deudas públicas de los países capitalistas avanzados como Inglaterra, Francia, Alemania y Estados Unidos eran, en su mayoría, internas. Rusia y España, en cambio, tenían importantes deudas externas, aunque es difícil precisar su monto para un año determinado. Entre los países del «Tercer Mundow, en 1873, los mayores deudores eran Turquía, Egipto y Perú. Asimismo, otros países como Canadá, Australia y la India tenían grandes deudas externas, pero con características especiales, ya que estaban sujetas al dominio británico. Sobre las deudas públicas europeas, véase D. C. M. Platt (1984), passim. Sobre las deudas de Turquía, Egipto y Perú, véase $H$. Clarke (1878). Sobre las deudas de los gobiernos provinciales australianos, véase el excelente estudio de A. R. Hall (1963). 


\section{CUADRO I}

Empréstitos extranjeros de los gobiernos latinoamericanos, 1850-1875 (Miles de libras esterlinas)

\begin{tabular}{|c|c|c|c|c|c|}
\hline \multirow[b]{2}{*}{ Pais } & \multirow[b]{2}{*}{$\begin{array}{c}\text { Total } \\
\text { préstamos }\end{array}$} & \multirow[b]{2}{*}{$\begin{array}{c}\text { Total } \\
\text { valor } \\
\text { nominal (1) }\end{array}$} & \multicolumn{3}{|c|}{ OBJETIVOS (2) } \\
\hline & & & $\begin{array}{c}\text { Militares } \\
\text { (\%) }\end{array}$ & $\begin{array}{c}\text { Obras } \\
\text { públicas } \\
\text { (\%) }\end{array}$ & $\begin{array}{c}\text { Refinancia- } \\
\text { miento (3) } \\
(\%)\end{array}$ \\
\hline Argentina . & 7 & 13.518 & 20 & 68 & 11 \\
\hline $\begin{array}{llllll}\text { Bolivia } & \ldots & \ldots & \ldots & \ldots & \ldots \\
\end{array}$ & 1 & 1.700 & - & 100 & - \\
\hline $\begin{array}{cccccc}\text { Burasil } & \ldots & \ldots & \ldots & \ldots & \ldots \\
\text { Bras } & \ldots & \ldots & \ldots\end{array}$ & 8 & 23.467 & 30 & 13 & 57 \\
\hline $\begin{array}{llllll}\text { Chile } & \ldots & \ldots & \ldots & \ldots & \ldots \\
\text { Chill } & \ldots & \ldots & \ldots & \ldots\end{array}$ & 7 & 8.552 & 37 & 51 & 12 \\
\hline $\begin{array}{ccccc}\text { Colombia } & \ldots & \ldots & \ldots & \ldots\end{array}$ & 2 & 2.200 & - & 9 & 91 \\
\hline $\begin{array}{lllll}\text { Costa Rica } & \ldots & \ldots & \ldots & \ldots \\
\end{array}$ & 3 & 3.400 & - & 100 & $\bar{a}$ \\
\hline Ecuador $\ldots$.. & 1 & 1.824 & - & $\overline{77}$ & 100 \\
\hline Guatemala $\ldots \ldots \ldots$ & 2 & 650 & - & 77 & 23 \\
\hline $\begin{array}{llllll}\text { Haití } & \ldots & \ldots & \ldots & \ldots & \ldots\end{array}$ & 1 & 1.458 & - & $\overline{0}$ & 100 \\
\hline $\begin{array}{lllll}\text { Honduras } & \ldots & \ldots & \ldots & \ldots\end{array}$ & 4 & 5.590 & - & 98 & 2 \\
\hline México $\ldots \ldots \ldots \ldots$ & 2 & 16.960 & 70 & - & 30 \\
\hline $\begin{array}{lllll}\text { Paraguay } & \ldots & \ldots & \ldots & \ldots\end{array}$ & 2 & 3.000 & - & 80 & 20 \\
\hline $\begin{array}{llllll} & \\
\text { Perú } & \ldots & \ldots & \ldots & \ldots & \ldots\end{array}$ & 7 & 51.840 & - & 49 & 51 \\
\hline Santo Domingo ......... & 1 & 757 & 一 & 100 & \\
\hline $\begin{array}{lllll}\text { Uruguay } & \ldots & \ldots & \ldots & \ldots\end{array}$ & 1 & 3.500 & - & $\overline{20}$ & 100 \\
\hline $\begin{array}{lllll}\text { Venezuela } & \ldots & \ldots & \ldots & \ldots\end{array}$ & 2 & 2.500 & 一 & 30 & 70 \\
\hline
\end{tabular}

Totales conjuntos de préstamos externos latinoamericanos por subperiodos

\begin{tabular}{|c|c|c|c|c|c|}
\hline \multirow[b]{2}{*}{ Años } & \multirow[b]{2}{*}{$\begin{array}{c}\text { Total } \\
\text { préstamos }\end{array}$} & \multirow[b]{2}{*}{$\begin{array}{c}\text { Total } \\
\text { valores } \\
\text { nominales }\end{array}$} & \multicolumn{3}{|c|}{ OBJETIVOS } \\
\hline & & & $\begin{array}{c}\text { Militares } \\
(\mathscr{\%})\end{array}$ & $\begin{array}{c}\text { Obras } \\
\text { públicas } \\
(\%)\end{array}$ & $\begin{array}{l}\text { Refinancia- } \\
\text { miento } \\
(\%)\end{array}$ \\
\hline $\begin{array}{llllll}1850-59 & \ldots & \ldots & \ldots & \ldots & \ldots \\
1860-69 & \ldots & \ldots & \ldots & \ldots & \ldots \\
1870-75 & \ldots & \ldots & \ldots & \ldots & \ldots\end{array}$ & $\begin{array}{r}9 \\
20 \\
22\end{array}$ & $\begin{array}{l}10.862 \\
56.705 \\
73.320\end{array}$ & $\frac{-}{40}$ & $\begin{array}{l}32 \\
13 \\
60\end{array}$ & $\begin{array}{l}68 \\
37 \\
40\end{array}$ \\
\hline
\end{tabular}

(1) El cuadro registra la suma aproximada de los valores nominales de los bonos externos emitidos. Dichos valores no son necesariamente la cifra real colocada, que en ocasiones era inferor. Por otra parte, en operaciones de refinanciamiento se intercambiaban bonos viejos por nuevos. De allí que la deuda exierna de cada país era mucho más reducida que los totales aquí consignados.

(2) Los nes de bonos tal como fue anunciado en los avisos oficiales de venta de los mismos. No renes de bonos tal como fue anunciado fondos efectivamente recibidos por los gobiernos. Solaflejan la verdadera distribución de los fondos efectivamente fuentes contables gubernamentales mente un estudio detallado de cada préstamo, utilizando fuentes cont

detalladas y confiables, podría proporcionar esta última información.

(3) Algunas operaciones de refinanciamiento no se incluyen aqui; por libras esterlinas de antiguas mexicana de 1851 (reconociendo aproximadamente 10 millones de libras esterlitan un par de deudas), ya que su implementación fue sumamente irregular. Asimismo, faltan un par de préstamos peruanos emitidos en Perú en los años

ción suficientemente precisa sobre los mismos.

Fuentes: Corporation of Foreign Bondholders, Annual Reports, Londres, 1873-1880; Charles FENN, A Compendium of the English and Foreign Funds..., Londres, edición de 1983; Hyde Clarke, "On the debts of sovereign and quasi-sovereign states, Owing by Foreign Countries", Journal of Statistical Society, vol. 41, pp. 313-319, Londres, 1878; Irving STONE. "The , "The composition and distribution of British investment in Latin America, Invesiments in Latin tesis doctoral, Columbia University, 1959. 
nos latinoamericanos debieron recibir por sus bonos. Si nos limitamos a los préstamos emitidos entre 1870 y 1875 , puede percibirse el alto diferencial entre un país y otro: Brasil, a cambio de vender títulos con valor nominal de 8,7 millones de libras, debió recibir 8,1 millones (es decir, 7 por 100 menos); Chile, vendiendo 3,4 millones, debió conseguir 2,9 millones (es decir, 13 por 100 menos); mientras que Guatemala por 500.000 recibiría solamente 350.000 (o sea, 30 por 100 menos) ${ }^{22}$.

Pero, aparte de las reducciones por cuenta de la diferencia entre valor nominal y precio efectivo, los gobiernos tenían que descontar otros gastos. En la mayoría de los casos existían acuerdos con los banqueros contratistas por los cuales éstos recibirían una comisión sobre ventas que podía variar entre 2 y 5 por 100 del valor nominal. En otros casos, los banqueros compraban los bonos a un precio bajo y luego intentaban obtener una suculenta ganancia mediante maniobras que empujasen el precio hacia arriba ${ }^{23}$. Pero en todos los casos, tanto las comisiones, como los gastos fijos, como las deducciones por reservas implicaban que el gobierno respectivo recibiera una suma sustancialmente reducida y, frecuentemente, en pagos escalonados.

Un ejemplo concreto servirá para ilustrar estos mecanismos. En 1871, el gobierno argentino negoció un gran empréstito de «obras públicas», con un valor nominal de 6,1 millones de libras esterlinas, con la casa bancaria de C. de Murrieta and Company de Londres. Los bonos comenzaron a venderse en la Bolsa de Londres a fines de ese mismo año, pero todavía en $1873 \mathrm{Mu}$ rrieta no había logrado colocar más de dos terceras partes del total. La cotización inicial había sido de 88 , pero a raíz de la crisis tendió a caer y, como consecuencia, las ventas posteriores (que continuaron hasta 1880) fueron menos rentables. En resumidas cuentas, al término de nueve años - después de iniciada la transacción- el gobierno argentino había recibido un total de 4,7 millones de libras ${ }^{24}$. En otras palabras, un 20 por 100 del valor nominal del empréstito fue absorbido por los gastos de venta y de comisiones de los banqueros. $Y$ éste era un ejemplo de un empréstito particularmente bien administrado, sobre el cual se publicó una gran cantidad de información para evitar críticas al gobierno.

En otros casos las condiciones de los empréstitos negociados fueron mucho más onerosas. El gobierno boliviano, por ejemplo, solicitó un empréstito por valor de 1,7 millones de libras, en 1871, con el objetivo de llevar a cabo

2 Los cálculos están basados en las cotizaciones de las ventas de los bonos tal como están consignadas en el Apéndice de este artículo.

${ }^{23}$ En el caso del empréstito de 1867 de Honduras, por ejemplo, el agente, C. Lefebvre, tomó el empréstito a 68 y luego pudo vender los bonos a 80 e inclusive a niveles más altos. Una buena descripción de sus operaciones se encuentra en W. Reader y J. Slimm (1980), pp. 7476.

24 Veanse fuentes citadas en la nota 20. Para detalles adicionales, Marichal (1983). 
un proyecto ambicioso, pero completamente irrealizable, que consistía en abrir una serie de vías de comunicaciones por medio de ferrocarriles, canales y ríos conectando el país, vía Brasil, con el Atlántico. Los bonos se colocaron a 68 por 100 , lo que dio un producto neto de apenas 800.000 libras, las cuales fueron entregadas al Bolivian Navigation Company, una empresa británica creada expresamente con el objetivo de llevar a cabo las grandiosas obras públicas proyectadas ${ }^{25}$. Sin embargo, debido a innumerables obstáculos, no se implementó el plan y, finalmente, en 1882 -después de largos litigios en los tribunales ingleses- el dinero fue devuelto a los tenedores de bonos.

Pero más allá de los numerosos ejemplos adicionales que podrían citarse acerca de asignaciones perjudiciales de fondos, hay que tener en cuenta que muchos de los empréstitos que se emitieron entre 1850 y 1873 no tenían un objetivo productivo, sino que se limitaban a la conversión de deudas anteriores todavía impagadas. Dichas conversiones no implicaban ninguna transferencia real de fondos de Europa a América Latina, sino sencillamente representaban el canje de bonos viejos por nuevos. En otras palabras, al sumarse las cifras oficiales de los empréstitos emitidos en el extranjero se corre el riesgo de proporcionar una cifra «inflada» del nivel real de endeudamiento.

El caso brasileño es particularmente ilustrativo de la importancia que podía alcanzar el refinanciamiento dentro del proceso global de endeudamiento externo. De un total de 23 millones de libras de bonos del gobierno imperial brasileño vendidos en Londres entre 1850 y 1875, nada menos que 13 millones fueron destinados a la conversión o devolución de anteriores deudas ${ }^{26}$. En otras palabras, el nivel de endeudamiento era sustancialmente inferior a lo que podría suponerse mediante el procedimiento equívoco de sumar los títulos emitidos. Pero de allí también se puede concluir que la transferencia neta de recursos financieros de Europa a Brasil fue, en efecto, bastante limitada en el período bajo estudio.

Si bien resulta manifiesto que hay que analizar con sumo cuidado las conversiones repetidas para efectuar una evaluación crítica del conjunto de préstamos gubernamentales latinoamericanos, también hay que prestar atención a otro tipo de empréstitos que tampoco cumplió un fin productivo. Nos referimos a los préstamos de guerra, los cuales fueron especialmente numerosos en la década de $1860-70$ debido a la multitud de conflictos bélicos en la región: la intervención francesa en México (1862-67), la intervención española en el Caribe y en la costa del Pacífico sudamericano (1865-66) y la guerra del Paraguay (1865-70), en la cual estuvieron involucradas las fuerzas aliadas de

${ }^{25}$ Para información referente a esta línea boliviana-brasileña, véase J. F. Rippy (1984), pp. 83-92. Para información sobre la renegociación de la deuda boliviana, consúltese Corporation of Foreign Bondholders (1876-1884).

${ }^{26}$ Véanse detalles en el Apéndice a este artículo. 
Brasil, Argentina y Uruguay contra el Estado paraguayo. En este último caso, no hay duda que los dos grandes empréstitos, argentino y brasileño, emitidos en Europa para financiar la guerra permitieron una transferencia efectiva de fondos que fueron utilizados para la compra de armamento, municiones, barcos de guerra y para pagar los salarios de oficiales y tropa ${ }^{27}$. Pero en otros casos no se produjo virtualmente ninguna transferencia.

Los dos grandes empréstitos emitidos en nombre del gobierno imperial de Maximiliano de México, en los años de 1864 y 1865, son ejemplos del fraude vinculado a determinados préstamos $y$, también, de la falta de escrúpulos de las potencias europeas en la utilización de dichas operaciones financieras para lograr sus objetivos imperiales. Ambas transacciones fueron avaladas por Fould, el ministro de finanzas de Napoleón III, con la finalidad ostensible de consolidar el régimen neocolonial de Maximiliano, pero con el verdadero objetivo de pagar los gastos de guerra de las tropas francesas que invadieron y ocuparon el territorio mexicano. El primer empréstito fue. colocado mediante un sindicato de banqueros anglo-franceses compuesto de las casas de Glynn-Mills, de Londres; del Credit Mobilier, de París, y de un consorcio financiero llamado la International Financial Society. En la práctica, más del 90 por 100 de los bonos se colocaron en Francia por falta de mercado en Gran Bretaña. Los inversores ingleses no se engañaban; sabían que se trataba sencillamente de una aventura imperial francesa. Dado el escaso éxito de este primer préstamo, Fould pidió al banco parisino, el Comptoir d'Escompte, que se encargara de una nueva transacción en 1865. Los nuevos bonos «imperial mexicanos» se vendieron con rapidez en la Bolsa de París durante varias semanas debido a la alta tasa de interés real que ofrecían, pero muy poco de este dinero se transfirió a México ${ }^{28}$.

De hecho, el recuento final de la asignación de fondos procedentes de estos empréstitos «mexicanos» indica que, aproximadamente, el 40 por $100 \mathrm{del}$ total fue utilizado para crear un gigantesco pool de reserva para los sindicatos bancarios, mientras que otro 40 por 100 fue transferido directamente al tesoro de Napoleón III para cubrir una parte de los costos de la invasión. A pesar del carácter netamente imperialista de estos empréstitos y de la derrota de Maximiliano poco después, los banqueros parisinos reclamaban la devolución de dineros que nunca habían llegado a México. Nada extrañamente, en 1867. el nuevo jefe de gobierno, Benito Juárez, declaró la suspensión de pagos indefinida sobre estas deudas. La declaración de moratoria sobre la deuda externa

${ }^{27}$ Sobre el empréstito de guerra argentino de 1865-68, negociado por la casa de Baring Brothers, puede consultarse D. C. M. Platt (1983), pp. 32-38.

"Sobre los empréstitos wimperial mexicanos», la mejor fuente de información es Geneviève Gille (1965). Para detalles adicionales, véase D. C. M. Platt (1982).

29 G. Gille (1965), pp. 221-222. 
por parte del gobierno mexicano anticipaba las acciones tomadas por otros Estados latinoamericanos en años posteriores. Pero, en estos últimos casos, la moratoria provino de otras causas, en especial de los efectos de la crisis internacional de 1873.

\section{El impacto de la crisis de 1873}

El auge de los préstamos externos latinoamericanos terminó asaz abruptamente con el estallido de la crisis internacional de 1873. Esta se desató a partir del desplome bursátil en mayo en Viena (entonces el tercer o cuarto mercado financiero más activo de Europa), siendo seguido por el crac en los mercados de capitales alemanes. En septiembre se produjo un pánico en la Bolsa de Nueva York que arrastró a varias importantes casas bancarias, entre ellas la de Jay Cooke and Company, una firma fuertemente comprometida en grandes negocios ferroviarios y en el financiamiento del gobierno federal. Ello rápidamente desencadenó una recesión económica en los Estados Unidos que se transformó luego en una prolongada depresión, durando hasta mediados de $1877^{30}$.

En Londres y París no hubo crisis financiera propiamente dicha en 1873, pero la inestabilidad internacional produjo una caída progresiva de las cotizaciones de los bonos de los empréstitos extranjeros y de otros valores. Estos movimientos bursátiles fueron acompañados por una gradual, pero sostenida, caída de los precios de productos industriales y de materias primas. El consiguiente retraimiento industrial, por otra parte, fue acentuado por una serie de crisis agrícolas - extensivas a la mayor parte de Europa-, produciendo una disminución de la actividad económica en todos los países capitalistas más avanzados.

Simultáneamente, la crisis golpeó a numerosos países de la "periferia dependiente», siendo especialmente fuerte el impacto en el Cercano Oriente y en América Latina. El cortocircuito financiero -que implicó una suspensión de nuevos empréstitos-y el descenso en las transacciones mercantiles internacionales generarò̀ una situación de crecientes dificultades para los gobiernos endeudados de estas zonas. Las suspensiones de pagos pronto comenzaron a estallar, y para 1875 se multiplicaron como reguera de pólvora. Los primeros países en declarar moratorias unilaterales sobre sus deudas fueron varios pequeños países latinoamericanos, siendo seguido a mediados del decenio por los tres mayores deudores del «tercer mundo» contemporáneo: Turquía, Egipto

${ }^{30}$ Para una buena descripción de la quiebra de Cooke, consúltese M. Josephson (1962), pp. $165-170$. 
y Perú. En efecto, se trataba de lo que podría denominarse la primera crisis mundial de la deuda ${ }^{31}$.

En América Latina los efectos de la crisis fueron variados. La caída de precios de las materias primas y productos primarios exportados afectó a virtualmente todas las economias, reduciendo los ingresos externos, forzando una disminución de las importaciones y provocando una caída en los ingresos fiscales. Pero no todas las naciones suspendieron pagos sobre sus deudas extranjeras. En Argentina, la crisis golpeó severamente a numerosas casas mercantiles de Buenos Aires y llevó a la quiebra de varios bancos locales en 1873 y 1874, pero, a pesar de ello, el gobierno logró extraer suficientes recursos como para pagar a sus acreedores con regularidad; en septiembre de 1876 la situación se tornó particularmente difícil, pero, merced a un préstamo "puente» de la casa Baring, el gobierno pudo cumplir con el pago semestral de intereses, y posteriormente el panorama económico fue mejorando ${ }^{32}$. En Chile la crisis tardó más tiempo en hacer estragos; no fue hasta fines de 1875 que en las Bolsas de Santiago y Valparaíso se denotaran síntomas serios de la tempestad financiera, que llevó a la quiebra a numerosas empresas mineras, inmobiliarias y bancarias ${ }^{33}$. Pero el gobierno chileno tampoco suspendió pagos y mantuvo su reputación en los mercados ingleses como cliente solvente y responsable. El gobierno imperial brasileño, por su parte, continuó cubriendo el servicio de la deuda (a pesar de varias fuertes quiebras bancarias en Río de Janeiro), ya que pudo solicitar y obtener un importante empréstito de refinanciamiento en el año de 1875, a pesar de una pronunciada baja en la Bolsa de Londres. El apoyo de la poderosa firma N. M. Rothschild, banqueros de la Corte brasileña, fue fundamental, pero también lo era el hecho de que las exportaciones de café, azúcar y algodón no decayeron demasiado abruptamente hasta 1876 , cuando el verdadero impacto de la crisis comenzó a sentirse con gran fuerza ${ }^{34}$.

La situación económica de los países más chicos de América Latina resultó ser más precaria que la de los grandes desde el inicio de la depresión. Ya en 1873, Costa Rica, Honduras, Paraguay y Santo Domingo se vieron obligados a declarar respectivas suspensiones de pagos. Y en 1874 siguieron Bolivia y Uruguay. El año siguiente Perú se declaró en bancarrota, hecho que sacudió a los mercados de capitales internacionales, ya que era el «gran deudor» latino-

${ }^{31}$ Para detalles sobre las deudas de los diferentes países, véanse los cuadros y comentarios de H. Clarke (1978).

${ }_{32}$ Sobre la crisis de 1873 en Argentina, véanse J. C. Chiaramonte (1971), cap. 5, y C. Marichal (1982), pp. $59-90$.

${ }_{33} W$. Sater (1979), pp. 67-99.

34 Las exportaciones brasileñas a Inglaterra, por ejemplo, bajaron de 7,4 millones de libras en 1875 a 5,2 millones en 1876, 6,3 millones en 1878 y 4,7 millones en 1879 . No se volvió a alcanzar la cifra de 1875 hasta 1905 . Para datos, véase D. C. M. Platt (1972), pp. 320-322. 
americano por la enorme cantidad de sus préstamos (véase cuadro I). La quiebra peruana sacudió al mercado londinense con tal fuerza que provocó un desplome generalizado de las cotizaciones de todos los valores latinoamericanos en ese mercado.

¿A qué puede atribuirse la intensidad del impacto financiero de la crisis en la región? Ya se han señalado varios elementos de tipo mercantil, pero en lo que se refiere específicamente al endeudamiento hay que tener en cuenta una serie de factores adicionales. En primer lugar, es menester reconocer que, si bien los gobiernos latinoamericanos habían recibido un flujo neto de recursos «reales» relativamente reducido en los años que precedieron a la debâcle financiera, estaban comprometidos a devolver la totalidad del valor nominal de los préstamos, además de un volumen alto de intereses. Pero la poca auspiciosa condición del fisco de las diversas naciones después de 1873 impedía la realización de estos pagos.

Que los países más pequeños no podrían devolver los empréstitos fue claramente reconocido desde fechas tempranas por los banqueros y los políticos británicos. De allí que se inició una investigación por parte del Parlamento inglés para determinar las causas que habían producido el excesivo endeudamiento y para aclarar el papel de los financieros y especuladores que habian contribuido a la creación de un mercado artificial para valores latinoamericanos que, ciertamente, no tenían garantías de devolución. Las investigaciones - publicadas en un grueso volumen en $1875^{35}$ - demostraron que un importante número de prestigiosas firmas financieras de Londres y París estaban involucradas en negocios turbios al respecto, al lado de varios especuladores inescrupulosos y de diversos agentes latinoamericanos carentes de cualquier sentimiento patriótico o ético. En su informe finai, los políticos ingleses no dudaron en echar una buena parte de la culpa del desastre financiero sobre las espaldas de los «irresponsables» gobiernos latinoamericanos, pero - $\mathrm{y}$ esto tiene un especial interés para el historiador del endeudamiento contemporáneo- hicieron explícitos los métodos irregulares y fraudulentos que utilizaron una multitud de banqueros europeos para inflar sus ganancias mediante la emisión de los bonos extranjeros.

Más allá de dichas transacciones netamente usurarias, otro elemento que contribuyó a intensificar el impacto de la crisis fue la abrupta reducción del flujo de capitales desde Europa hacia América Latina. Ello implicaba que resultase extremadamente difícil después de 1873 el obtener nuevos empréstitos con los cuales refinanciar los antiguos préstamos, pendientes de pago. Como se ha observado ya a partir de las cifras y fluctuaciones dibujadas en el gráfico I, la caída de los flujos de capital fue sustancialmente más drástica que

\footnotetext{
3s Parliamentary Papers (1875).
} 
la de mercancía. Y ello afectaba, en primera instancia, a los gobiernos deudores.

Por último, es pertinente efectuar algunos comentarios acerca de la evolución financiera de Perú, teniendo en cuenta el gigantesco peso de su deuda. La economía peruana no resintió la crisis de manera inmediata por varios motivos, entre los cuales el más importante era el hecho de que el valor de sus exportaciones totales no disminuyó entre 1873 y 1876, sino que, algo paradójicamente, aumentó ${ }^{36}$. El descubrimiento y la explotación intensa de nuevos depósitos de nitratos compensó la relativa languidez de las exportaciones de guano, y, al mismo tiempo, las exportaciones de azúcar se convirtieron en un rubro importante. Para fines de 1875 , no obstante, el Estado peruano se enfrentaba con la amenaza de la bancarrota. ¿A qué se debía esta gravísima crisis? El problema estribaba fundamentalmente en el hecho de que los recursos principales del gobierno provenían del sector guanero, que era estatal; en cambio, el negocio de los nitratos, el algodón, el azúcar y la lana eran manejados por empresarios privados. Los políticos peruanos habían fundado sus ambiciosos proyectos de desarrollo económico (fundamentalmente la construcción de ferrocarriles, extremadamente costosos, y la modernización del puerto de Callao) en el financiamiento proveído por los ingresos guaneros. Pero, desde 1869, habían entregado tales recursos a la firma francesa Dreyfus Frères a cambio de que ésta se encargara de controlar nuevos empréstitos y de cubrir los pagos sobre los viejos. La saturación del mercado de fertilizantes en Europa, aunada a la caída de los precios del guano, sin embargo, hicieron cada vez más difícil obtener los fondos solicitados por el gobierno ${ }^{37}$.

En 1876, por lo tanto, las autoridades de Lima se encontraron ante la necesidad de declarar la suspensión de pagos. Intentaron varias medidas de rescate, entre ellas la nacionalización de las empresas mineras de nitrato, pero ninguna dio un resultado feliz. Por otra parte, hacia finales del decenio comenzaron los pleitos con Chile alrededor de la cuestión del control de los campos de nitrato, y en 1879 estalló la guerra del Pacífico, que llevaría a la derrota militar peruana y a la pérdida de una gran parte de su territorio. Lo que había comenzado como una crisis financiera se convirtió eventualmente en un desastre político, social y militar, provocando, a su vez, el inicio de una prolongada depresión económica de la cual Perú no se recuperaría durante, al menos, dos decenios.

36 Las exportaciones de nitratos peruanos aumentaron de 3,6 millones de libras en 1873 a 5,2 millones en 1876; las exportaciones de azúcar aumentaron de 663.000 libras esterlinas en 1873 a 1,5 millones en 1877 . Véase Marichal (1982), p. 88.

${ }^{37}$ Sobre los negocios relacionados con los empréstitos peruanos, véanse W. Wynne (1952), pp. 107-197; W. Stewart (1946) y H. Bonilla (1974). 
Las renegociaciones: ¿cómo se pagaron las deudas?

Como ya se ha indicado, los tres países de América Latina con mayor nivel de comercio exterior, Argentina, Brasil y Chile, no suspendieron pagos a raíz de la depresión de los años de 1870. Ello puede atribuirse en esencia al hecho de que los gobiernos de estas naciones disponían de suficientes recursos (en su mayoría provenientes de los impuestos sobre importaciones) como para garantizar el pago de intereses y amortización sobre sus deudas externas. Pero igual suerte no tuvieron los demás Estados latinoamericanos.

Para principios de 1876, al menos once países de la región habían sus. pendido pagos sobre sus obligaciones externas. Entre éstos, tres ya habían declarado una moratoria antes de la crisis de 1873: Venezuela, en 1866; México, en 1867, y Ecuador, en 1868. Los demás países, que incluían a Bolivia, Costa Rica, Guatemala, Honduras, Paraguay, Perú, Santo Domingo y Uruguay, entraron en bancarrota entre 1873 y 1876 . De éstos, solamente Uruguay pudo reiniciar las remesas de intereses para los acreedores europeos antes de 1880 . Los demás, en cambio, se enfrentaron con largos y conflictivos litigios que tardaron (en algunos casos) decenios por resolverse.

Resulta imposible en este corto ensayo seguir en detalle los tortuosos pasos de las negociaciones entre los gobiernos y los acreedores extranjeros. Pero podemos, al menos, intentar describir cuáles fueron las líneas centrales de este forcejeo. Para comenzar hay que tener en cuenta quiénes eran los protagonistas principales de estos pleitos financieros internacionales. De un lado estaban los tenedores de bonos, representados por los Comités de Tenedores de Bonos Extranjeros, de los cuales el más importante era, indudablemente, el comité británico, aunque en varias instancias los comités francés y holandés tomaron un papel activo en las discusiones ${ }^{38}$. Los tenedores solían contar con el apoyo informal de sus respectivos gobiernos, pero en la práctica las cancillerías europeas no intervinieron en este período en dichos diferendos. Más consistente era la colaboración entre tenedores y banqueros, estos últimos siendo propietarios de un porcentaje variable de los bonos impagos. Pero en diversos casos - como fueron los de Costa Rica y Perú- ejercieron un rol más importante determinados ambiciosos y astutos empresarios que encontraron en las renegociaciones una oportunidad inigualada para ampliar sus negocios en uno o más paises de la región.

Por el otro lado estaban los gobiernos deudores, los cuales fueron cam-

Los informes anuales de la Corporation of Foreign Bondholders, de Londres, se publicaron con regularidad desde 1873 , proporcionando una gran cantidad de información sobre estas negociaciones. Los informes de los comités francés y holandés son más difíciles de localizar, pero, asimismo, contienen información valiosa sobre el tema, debiendo ser objeto de estudio en el futuro. 
biando de posición, adoptando políticas más o menos flexibles de acuerdo con la coyuntura política o económica. Entre 1875 y mediados del decenio 1880, la penuria de la mayoría de los Estados era tan acuciante que ni siquiera pudieron intentar la reiniciación de pagos sobre los préstamos de manera sistemática. Por otra parte, los complicados litigios daban pie a los representantes de los diferentes gobiernos para prolongar la suspensión de pagos sobre una amplia gama de deudas que, en muchos casos, eran realmente espurias. Pero entre 1885 y 1890 se produjeron una serie de cambios políticos y económicos que ablandó la intransigencia de los ministros de finanzas latinoamericanos. $\mathrm{El}$ aumento generalizado de las exportaciones de materias primas de la región y la creciente oferta de capitales en los mercados financieros europeos indujo a los gobernantes a buscar nuevos arreglos. El atractivo de un pacto consistía en que podía estimular una nueva corriente de recursos hacia el país en cuestión, estimulando el desarrollo económico. No obstante, en la mayoría de los casos los acuerdos fueron perjudiciales, agravando la dependencia financiera.

El primer convenio ratificado fue aquel firmado por el gobierno de Bolivia y sus acreedores en 1882; después, en 1885, siguieron los pactos de Costa Rica y Paraguay, y, durante 1886-88, los gobiernos de México, Guatemala, Ecuador, Santo Domingo y Venezuela llegaron a sendos acuerdos con los banqueros europeos. El Estado peruano, en cambio, no pudo concluir sus negociaciones hasta 1890, y las autoridades de Honduras todavía estaban en litigios con los tenedores a fines del siglo ${ }^{39}$.

Debe tenerse en cuenta que la falta de recursos no fue el único motivo que impulsó a los sucesivos gobiernos a prolongar los pleitos. Dos factores adicionales ejercieron un peso preponderante. El primero era que un buen número de los empréstitos no habían proporcionado una transferencia de recursos equiparable en grado significativo al monto total de las deudas reclamadas. Muchos préstamos, como ya se ha visto, habían sido emitidos a 60 ó 70 por 100 de su valor nominal, y con frecuencia el producto neto ascendió a menos del 50 por 100 del supuesto valor del empréstito. De allí que, en las negociaciones con los tenedores (dentro y fuera de los tribunales europeos), los agentes latinoamericanos podian argumentar que los banqueros involucrados habían realizado enormes e indebidas ganancias con dichas transacciones ${ }^{*}$. Por otra parte, era un hecho reconocido que los inversores, al arriesgarse a invertir en títulos con cotización baja y tasas de interés altas, estaban participando de negocios fuertemente especulativos.

Un segundo elemento que instaba a las autoridades latinoamericanas a

${ }^{39}$ Véanse detalles en Corporation of Foreign Bondholders (1895 y 1898).

- El estudio más detallado de los litigios entre los acreedores y los gobiernos de Santo Domingo y Perú se encuentra en W. Wynne (1952), II, pp. 1-280. 
postergar la resolución de los diferendos se vinculaba con la oposición política interna que habían generado los préstamos. Era sabido que no sólo los banqueros se enriquecieron con dichos negocios, sino que, además, numerosos políticos y burócratas fueron cómplices. La prepotencia de algunos gobernantes fue tal que en ocasiones se jactaron de estas hazañas. El general Guardia de Costa Rica, por ejemplo, reconoció en sendas sesiones de la legislatura local que había recibido regalos personales de 100.000 libras esterlinas por el empréstito de 1871 y otras 60.000 por el de 1872, afirmando que ello era costumbre en este tipo de operación y que los fondos que él recibiera se destinaban a objetivos legítimos ${ }^{41}$. No obstante, las administraciones políticas posteriores no podían defender tan turbios negocios sin exponerse a la cólera popular. Inevitablemente se vieron obligados a realizar algunos gestos de protesta para salvar, al menos, la apariencia de su pundonor.

En última instancia, sin embargo, las disputas financieras se resolvieron por medio de acuerdos que generalmente fueron desfavorables para los deudores y relativamente favorables para los acreedores. En efecto, los gobiernos deudores tenían que efectuar concesiones si deseaban elevar su crédito externo y propiciar una nueva corriente de capitales extranjeros. Al no contar con suficientes recursos fiscales para liquidar las deudas, les quedaban solamente dos soluciones alternativas para resolver los diferendos. Por un lado, podían emitir nuevos bonos a cambio de los viejos, garantizando el pago de intereses y amortización mediante la hipoteca de algunos impuestos claves. Este fue el camino elegido, por ejemplo, por el gobierno de Heureaux en Santo Domingo, quien en 1888 aceptó emitir 770.000 libras en nuevos bonos (cancelándose los antiguos) a través de la Westendorp Corporation, que, dicho sea de paso, asumió el control de las finanzas del Estado mediante la administración directa de una "Caja de Recaudación», especie de administración fiscal neocolonial ${ }^{42}$.

Por otro lado, los ministros podían intentar canjear propiedades del Estado por deuda. Esta última solución fue la adoptada por los gobiernos de Costa Rica y Perú, entre otros. En Costa Rica, el empresario ferroviario Minor Keith logró convencer a las autoridades hacendistas que podían reducir el importe de la deuda pendiente de pago si le entregaban las cortas líneas ferroviarias ya construidas y una concesión por noventa y nueve años para completar y administrar el sistema ferroviario nacional; a ello se agregaba la entrega de unas 230.000 hectáreas de tierra colindantes con las vías proyectadas. Después de lograr el consentimiento de la élite política en San José, Keith

" El texto completo de la declaración de Guardia fue reproducido en Parliamentary Papers (1875), pp. 153-155. Para información adicional, véase W. Stewart (1964), pp. 812, 26-29.

${ }^{42} \mathrm{~W}$. Wynne (1952), II, pp. 204-210; para detalles adicionales, véanse S. Welles (1928) y C. Herrera (1953), pp. 293-297. 
viajó a Europa y, al cabo de dos tediosos años de negociaciones, logró persuadir a los tenedores de bonos costarricenses de las bondades de su plan. Ellos recibirían 2 millones de libras en nuevos bonos y una tercera parte de las acciones en la nueva empresa centroamericana de ferrocarriles ${ }^{43}$. No está de más señalar que estas concesiones sirvieron de cimiento para la creación, diez años más tarde, por Keith y sus socios de la United Fruit Company ${ }^{44}$.

En Paraguay la solución adoptada fue similar. En 1885, el gobierno paraguayo aceptó un pacto por el cua! se reduciría el valor de la deuda externa, de 3 millones de libras a 800.000 , a cambio de entregar 1 millón de hectáreas de tierras y bosques a la Corporación de Tenedores de Bonos Extranjeros ${ }^{45}$. Poco después, los miembros interesados de esta última entidad propiciaron la creación del Anglo-Paraguay Land and Cattle Company, el cual se convirtió en una fuerza poderosa dentro de la economía regional durante varios decenios.

Por último, debe subrayarse que las concesiones efectuadas en el caso de Perú fueron mayores todavía, lo cual no era extraño dado el enorme volumen de su deuda externa y la cifra abultada de los intereses atrasados desde la moratoria en 1876. Después de años de litigios entre el gobierno de Lima y la Corporación de Tenedores de Bonos de Inglaterra se pudo negociar una solución merced a los esfuerzos de un capitalista norteamericano, Michael Grace. El acuerdo, conocido como el «Contrato Grace» de 1890, ratificó la liquidación de la mayor parte de la deuda peruana a cambio de las entregas de propiedades estatales a una nueva empresa de capital británico llamada la Peruvian Corporation. Por este convenio el gobierno cedió a la firma británica todos los ferrocarriles estatales (unos $770 \mathrm{~km}$. de líneas transandinas); 2 millones de toneladas de guano; una concesión para operar una línea de vapores en el Lago Titicaca, incluyendo las naves gubernamentales ya existentes; $2 \mathrm{mi}$ llones de hectáreas de tierras, y concesiones relativas a la explotación de las ricas minas de Cerro de Pasco ${ }^{46}$. Pero, aun así, los litigios no habían concluido. Los tenedores franceses - que no fueron incluidos en este contratoreclamaron la devolución de sus fondos. De hecho, no fue hasta 1910 que el gobierno francés logró que Perú comenzara a pagar los 3,4 millones de libras adeudadas a la firma de Dreyfus Frères desde fines de los años de 1870 . Y no fue hasta 1925-26 que se terminaron de efectuar los pagos sobre esta deuda ya casi secular ${ }^{4}$.

${ }^{4}$ Sobre estas transacciones hay información en W. Stewart (1964), pp. 55-59; H. Bischoff (1953), pp. 29-40; C. González Viquez (1977) y T. Soley Guell (1947), pp. 339-341.

4 Vease S. Macy y G. Plaza (1954), pp. 8-12.

${ }^{4} \mathrm{H}$. G. Warren (1972), pp. 3-24.

to Para un análisis detallado de los aspectos legales del Contrato Grace, consúltese W. Wynne (1951), II, pp. 159-175. Para una interpretación de carácter económico, véase R. Miller (1983).

${ }^{47}$ W. Wynne (1951), II, pp. 168-170. 
En resumidas cuentas, las consecuencias del boom del endeudamiento externo latinoamericano de los años de $1850-73$ y las consecuencias inesperadamente despiadadas de la crisis internacional que siguió habían de generar una serie de problemas políticos y económicos de enorme complejidad para los países latinoamericanos. Esta crisis financiera de 1873-76, que podemos calificar como la primera crisis internacional de la deuda externa, reflejaba los traumas y las contradicciones del modo de producción capitalista que comenzaba a considerarse en la región, generando ciclos alternativos y aparentemente inevitables de desarrollo y subdesarrollo.

\section{BIBLIOGRAFIA}

Baxter, Dudley (1874): «The Recent Progress of National Debts», Journal of the Statistical Society, XXXVII, pp. 1-20, Londres.

Bisc h OFF, Henry C. (1953): "British Investment in Costa Rica», Inter American Economic Affairs, VII, núm. 1, pp. 37-47.

Bonilla, Heraclio (1974): Guano y burguesía en el Perú, Lima, Instituto de Estudios Peruanos.

CAIRnCross, Alexander K. (1953): Home and Foreign Investment, 1870-1914: Studies in Capital Accumulation, Cambridge (Inglaterra), Cambridge University Press.

CLARKE, Hyde (1878): "On the Debts of Sovereign and Quasi-Sovereign States Owing by Foreign Countriesw, Journal of the Royal Statistical Society, XLI, pp. 249-347, Londres.

Corporation of Foreign Bondh olders (1873-): Annual Report, Londres.

Chiaramonte, José Carlos (1971): Nacionalismo y liberalismo económicos en Argentina, 1860-1880, Buenos Aires, Ed. Solar Hachette.

FeIs, Herbert (1930): Europe, The World's Banker, New Haven, Yale University Press. FORD, Alec G. (1966): El patrón oro: 1880-1914. Inglaterra y Argentina, Buenos Aires, Instituto Di Tella.

GifFEN, Robert (1904): "The Liquidations of 1873-1876», en su libro Economic Inquiries and Studies, I, pp. 98-120, Londres.

Gille, Geneviève (1965): «Les capitaux français et l'expedition de Mexique», Revue d'Histoire Diplomatique, pp. 193-251.

GonzÁlez Viquez, Cleto (1977): Capitulos de un libro sobre bistoria financiera de Costa Rica, San José.

Hall, A. R. (1963): The London Capital Market and Australia, 1870-1914, Canberra, Australian National University.

- (ed.) (1968): The Export of Capital from Britain, Londres, Methuen.

Herrera, César A. (1947): «El empréstito Harmont», Boletín del Arcbivo General, X, pp. 266-274, Santo Domingo.

HoBson, Charles (1914): The Export of Capital, Londres.

ImLA H, Albert (1958): Economic Elements in the Pax Britannica: Studies in Britisb Foreign Trade in the 19th Century, Cambridge (Mass.), Harvard University Press.

Jenks, Leland (1927): The Migration of British Capital to 1875, Nueva York.

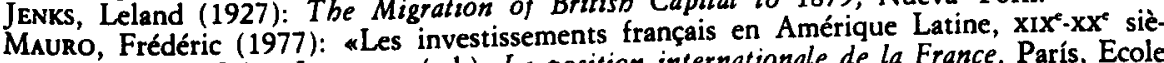
cles», en M. LÉVy LEBoyer (ed.): La position internationale de la France, París, Ecole des Hautes Etudes en Sciences Sociales, pp. 193-202. 
JOSEP H SON, Mathew (1962): The Robber Barons, Nueva York, edición original de 1930. MACY, S., y Plazı, G. (1954): The United Fruit Company in Latin America, Nueva York. Maric hal, Carlos (1980): «Perspectivas históricas sobre el imperialismo financiero en América Latina», Economía de América Latina, núm. 4, pp. 13-44, México, Centro de Investigación y Docencia Económica.

- (1982): "La crisis de 1873 en América Latina: los casos de Argentina, Chile y Perú», Iztapalapa, Revista de Ciencias Sociales, III, 6, pp. 59-90, México.

- (1983): *The State and Economic Development in Argentina under Sarmiento and Avellaneda, 1868-1880m, trabajo presentado en el American Historical Association, Annual Meeting, San Francisco, 27.29 de diciembre.

Miller, Rory (1983): "The Grace Contract, the Peruvian Corporation and Peruvian Historyn, Ibera-Amerikanisches Archiv, 9, 3/4, pp. 319-347.

PaISH, George (1977): «Great Britain's Investment in Other Lands», artículo de 1911, reimpreso en Mira Wilkins: British Overseas Investments, 1907-1948, Nueva York, Arno Press.

Parliamentary Papers (1875): «Report from the Select Committee on Loans to Foreign Statesw, XI, 15, Londres.

Platt, D. C. M. (1972): Latin America and British Trade, 1806-1914, Londres, Adam and Charles Black.

- (1980): «British Portfolio Investment Overseas Before 1870: Some Doubts», Economic History Review, 33, 1, pp. 1-16.

- (1982): «Las finanzas británicas en México, 1821-1867», Historia Mexicana, núm. 126, pp. 226-261.

- (1983): «Foreign Finance in Argentina for the First Half-Century of Independence», Journal of Latin American Siudies, 15, 1, pp. 23-47.

- (1984): Foreign Finance in Continental Europe and the USA, 1815-1870, Londres, Allen and Unwin.

Reader, W. J., y Slimm, J. (1980): A House in the City: A Study of the City and the Stock Excbange based on the records of Foster and Braitbwaith, Londres.

Rippy, J. F. (1944): Latin America and the Industrial Age, Nueva York.

SATER, William F. (1979): "Chile and the World Depression of the 1870's", Journal of Latin American Studies, II, 1, pp. 67-99.

Simon, Mathew (1968): "The Pattern of New British Portfolio Foreign Investment, 1865-1914w, en A. R. Hall, The Export of Capital from Brilain, 1870-1914, pp. 15-44.

Soley Guell, Tomás (1947): Historia económica y bacendaria de Costa Rica, I, San José.

StewarT, Watt (1946): Henry Meiggs, Yankee Pizarro, Durham, North Carolina.

- (1964): Keith and Costa Rica: A Biograpbical Study of Minor Cooper Keith, Alburquerque, University of New Mexico Press.

Stone, Irving (1962): "The Composition and Distribution of British Investments in Latin America, 1865-1913m, tesis doctoral, Columbia University.

- (1977): «British Direct and Portfolio Investment in Latin America Before 1914», Journal of Economic History, XXXVII, 3, pp. 690-722.

WARREN Harris, Gaylord (1972): *The Golden Fleecing of the Paraguayan Loans of 1871 and 1872\%, Inter American Economic Affairs, 26, pp. 3-24.

Welles, Sumner (1928): Naboth's Vineyard, the Dominican Republic, 1844-1924, Nueva York, 2 vols.

Williams, John H. (1920): Argentine International Trade Under Inconvertible Currency, 1880-1900, Cambridge (Mass.), Harvard University Press.

WYNNE, William (1951): State Insolvency and Foreign Bondholders, 2 vols., New Haven, Yale University Press. 


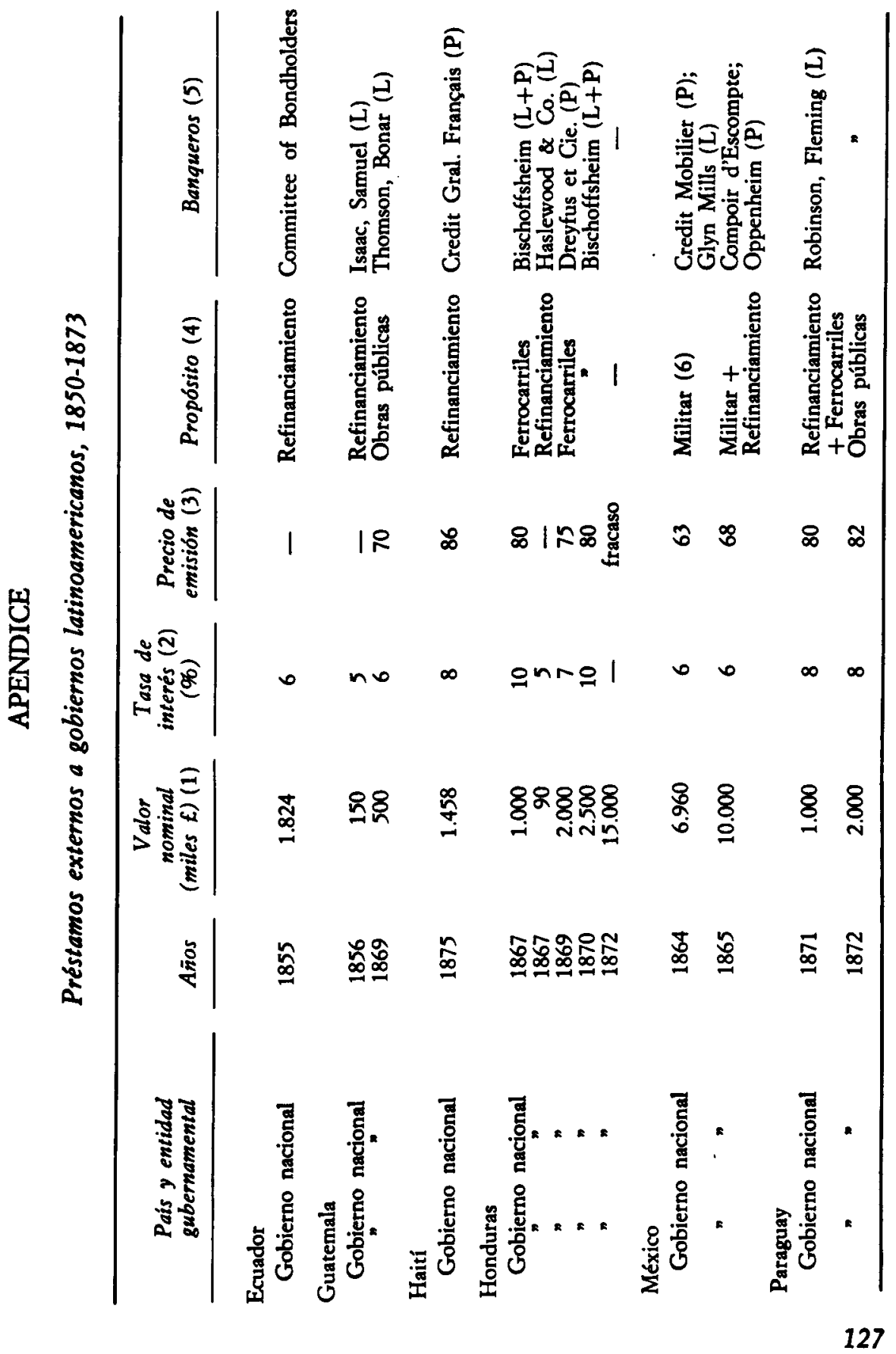




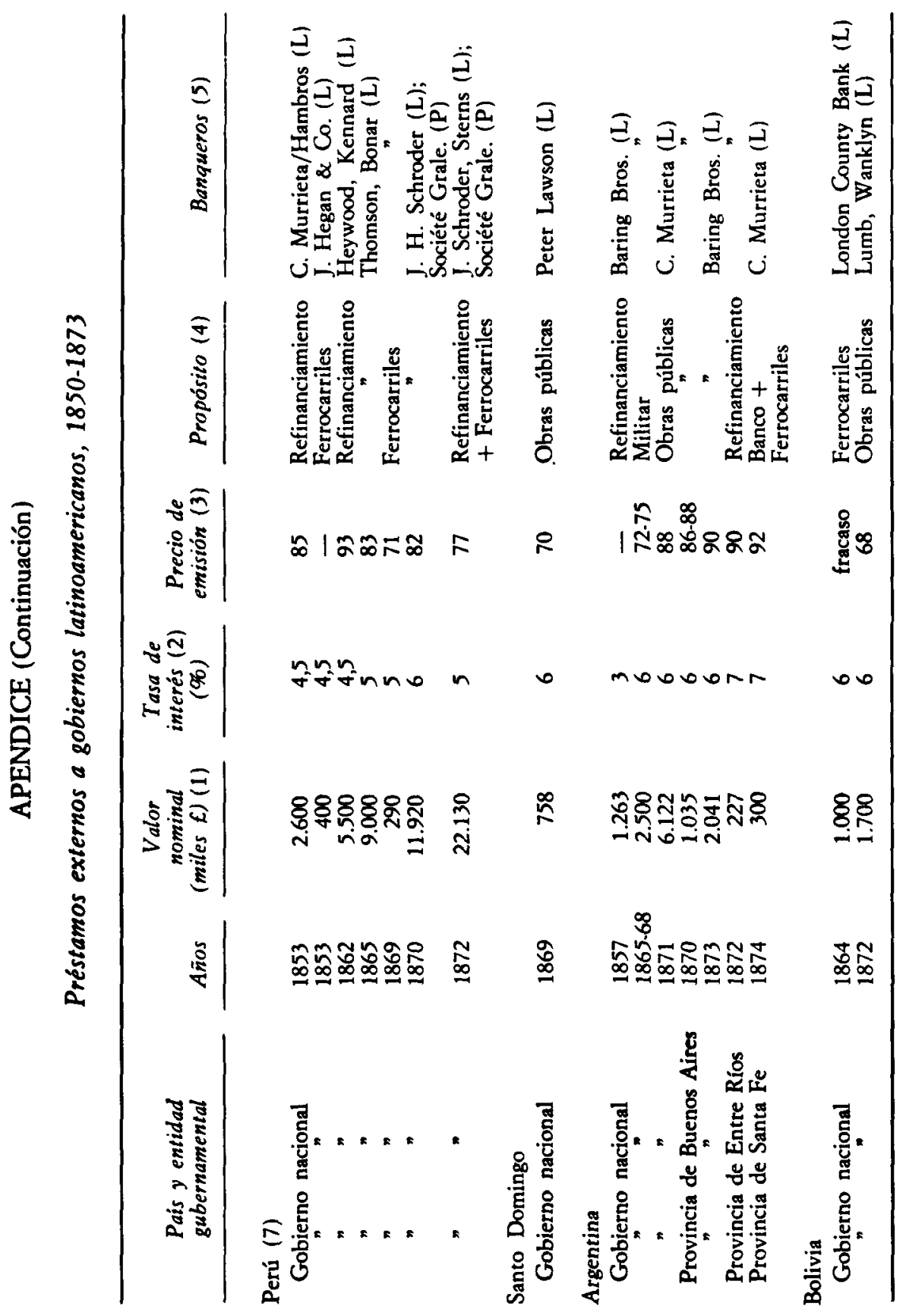




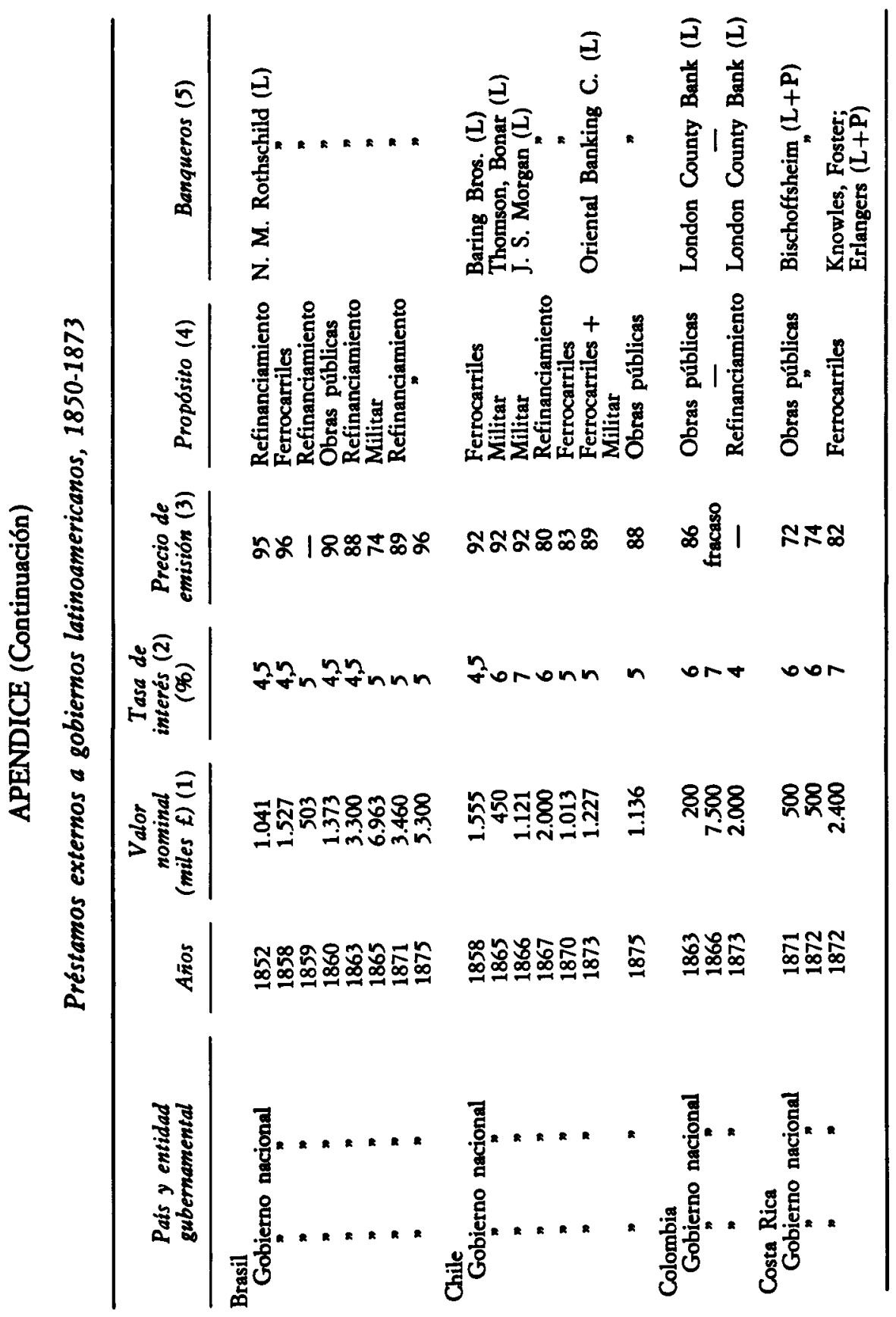




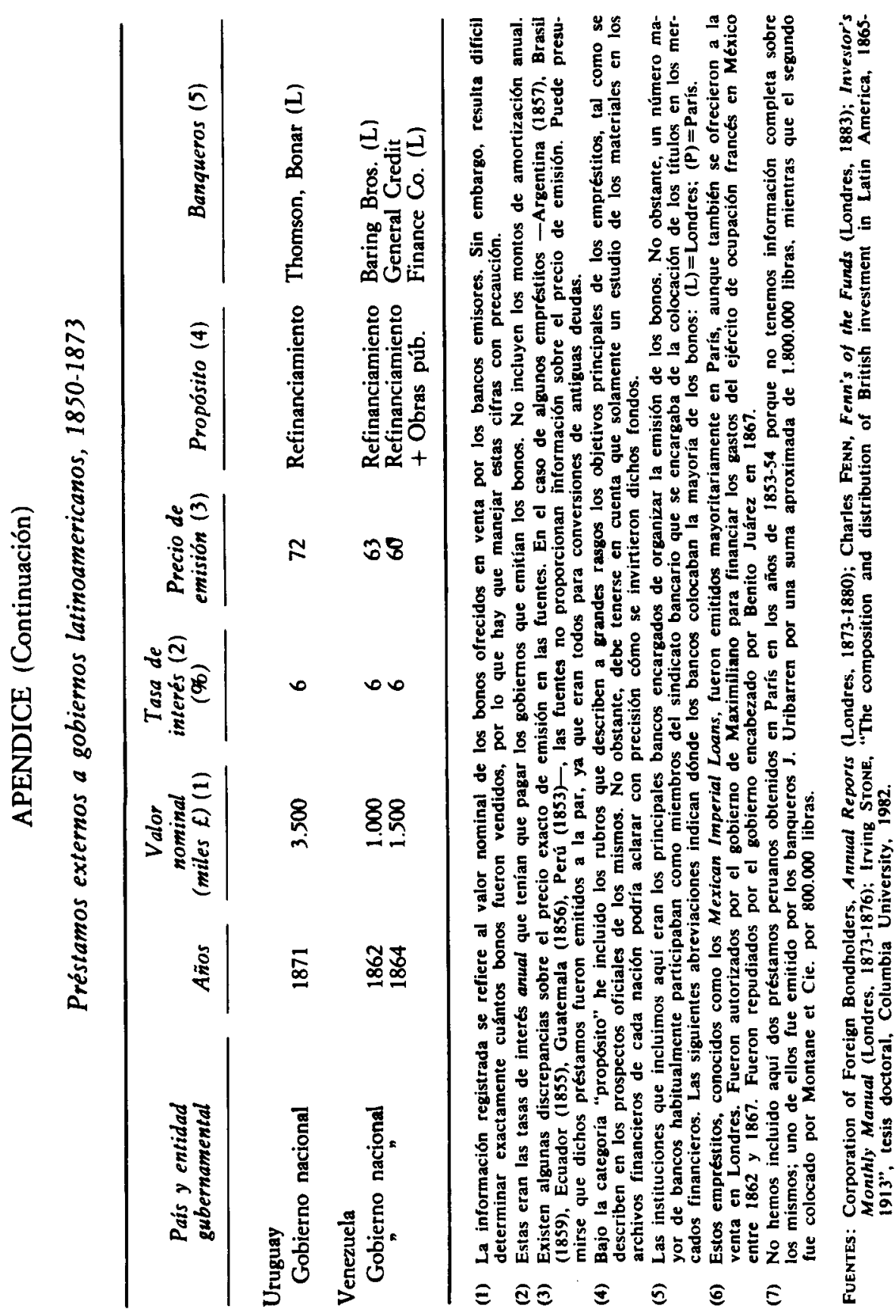

